\title{
PRODUÇÃO DE SENTIDOS E POSICIONAMENTO POLÍTICO NA MIIIDIA IMPRESSA BRASILEIRA
}

\author{
PRODUCCIÓN DE SENTIDOS Y DE POSICIONAMIENTO \\ POLÍTICO EN MEDIOS IMPRESOS BRASILEIROS \\ PRODUCTION OF MEANINGS AND POLITICAL \\ POSITIONING IN BRAZILIAN PRINT MEDIA
}

\author{
Paulo Roberto de Carvalho ${ }^{1}$ e Alexandre Bonetti Lima ${ }^{1}$ \\ ${ }^{1}$ Universidade Estadual de Londrina, Londrina/PR, Brasil
}

\begin{abstract}
RESUMO: O presente estudo tem como objetivo analisar o papel da mídia impressa jornalística na produção de discursos e sentidos sobre o acontecimento histórico que foi o afastamento da presidente Dilma Rousseff de suas funções. A análise compreende e enfoca o posicionamento político adotado por um jornal e sua disponibilidade para veicular posições diferentes daquelas adotadas por esse órgão de comunicação. Para fins de análise, foi selecionado o jornal Folha de S. Paulo, de grande circulação e com presença significativa no cenário nacional. O conteúdo do jornal, bem como suas manchetes e capas, foram examinados tanto sob o enfoque quantitativo quanto qualitativo. Resultou que o jornal mantém um posicionamento uniforme e contrário ao governo eleito e destituído, o que é compartilhado com outros órgãos de comunicação. Como resultado, pode-se dizer que esse fato faz parte de um processo político de dominação realizado no âmbito da comunicação, contrariando os princípios democráticos.
\end{abstract}

PALAVRAS-CHAVE: Mídia; Sentido; Psicologia Social.

RESUMEN: Este estudio pretende analizar el papel de los medios periodísticos impresos en la producción de discursos y sentidos sobre el evento histórico que fue la alejamiento de la Presidenta Dilma Rousseff de sus funciones. El análisis comprende y enfoca el posicionamiento político adoptado por un diario y su disponibilidad para difundir posiciones diferentes de las adoptadas por ese órgano de comunicación. Para efectos del análisis, se seleccionó el diario Folha de S. Paulo, de circulación masiva y significativa presencia en la escena nacional. El contenido del periódico, así como sus titulares y portadas, se examinaron tanto bajo el enfoque cuantitativo y cualitativo. Se reveló que el diario mantiene un posicionamiento uniforme y contrario al gobierno electo y destituído, compartillado por otros medios. Como resultado, puede decirse que este hecho forma parte de un proceso político de dominación realizado en el ámbito de la comunicación, contrariando a los principios democráticos.

PALABRAS CLAVE: Medios de comunicación; Sentido; Psicología social.

ABSTRACT: This study aims to analyze the role of journalistic print media in the production of discourse and meanings about the historic event that was the removal of President Dilma Rousseff from her duties. The analysis consisted of and focused on the political position adopted by a newspaper and its availability to serve positions different from those adopted by this organ of communication. For analysis purposes, the Folha de $\mathrm{S}$. Paulo newspaper, which is widely circulated and has a significant presence on the national scene, was selected. The content of the newspaper, as well as its headlines and magazine covers, were examined under the quantitative and qualitative focuses. The analysis resulted in the newspaper maintaining a uniform contrary position to the elected and removed government, a result that is shared with other media. As a result, it can be said that this fact is part of a political process of domination carried out within the scope communication, which goes against democratic principles.

KEYWORDS: Media; Sense; Social Psychology. 


\section{Introdução}

A Psicologia Social, como campo constituído de investigação, comporta um leque de temas variados sempre considerados sob o enfoque histórico. Dentre os objetos de estudo desta área do conhecimento, o conceito de instituição ocupa um papel de destaque por sua amplitude e complexidade, mas também por sua presença em todos os contextos da vida em sociedade. Instituições como a família e a escola, por exemplo, são objetos clássicos e extensamente analisados. Por outro lado, em uma perspectiva histórica, a Psicologia Social constrói uma abordagem crítica daquelas instituições que, no período analisado, ganham importância estratégica, intervindo de modo decisivo na realidade social, política e econômica do país. Nas últimas décadas, a presença cada vez mais relevante das mídias nas relações sociais tem despertado o interesse da Psicologia Social para o processo pelo qual elas intervêm na constituição dos sujeitos, no contexto de uma contemporaneidade capitalística.

Este é o caso do presente estudo, que coloca em foco o meio jornalístico brasileiro, elegendo como objeto para um exame sistemático o jornal Folha de S. Paulo, o diário de maior circulação do Brasil. O escopo desta análise restringe-se ao noticiário oferecido pelo jornal sobre um acontecimento político da história recente do Brasil, que é a eleição da presidente Dilma Rousseff, no fim de 2014, bem como o período subsequente de aproximadamente um ano e oito meses.

Eis então porque, diante de um acontecimento histórico ainda em curso e que, por isso mesmo, demanda análise, optou-se pela elaboração de um estudo realizado sob o enfoque psicossocial. A eleição, seus desdobramentos e a evolução do governo eleito, na forma que comparecem na mídia jornalística brasileira, serão colocados em questão. O jornal Folha de S. Paulo, editado no estado de São Paulo, com circulação em todas as regiões do país, apresenta-se em sua página institucional eletrônica nos seguintes termos:

\section{O JORNAL MAIS INFLUENTE DO PAÍS.}

Fundada em 1921, a Folha é, desde a década de 80, o jornal mais vendido do país entre os diários nacionais de interesse geral. O crescimento foi calcado nos princípios editoriais do Projeto Folha: pluralismo, apartidarismo, jornalismo crítico e independência.

Organizado em cadernos temáticos diários e suplementos, tem circulação nacional. Foi o primeiro veículo de comunicação do Brasil a adotar a figura do ombudsman e a oferecer conteúdo online a seus leitores (Folha de S. Paulo, Institucional).

A Folha de S. Paulo é, de fato, o jornal com a maior tiragem do país (média de 320.741 exemplares diários, em agosto de 2015, segundo o Instituto Verificador de CirculaçãoIVC). Em relação à versão digital, o instituto assinala que o número de páginas vistas em março de 2016 chegou a 475 milhões, enquanto que e o número de visitantes, no mesmo período, foi de 42,6 milhões. Esta posição possibilita, em tese, que se presentifique maior diversidade de vozes nas suas páginas, alcançando, assim, maior representatividade com relação aos temas e notícias de que trata. Isso ocorre porque os jornais de grande circulação frequentemente mostram-se menos rígidos com relação à sua linha editorial e mais tolerantes às posições divergentes, à medida que se dirigem a um número mais extenso e heterogêneo de leitores. 
Metodologicamente, este estudo combinou uma abordagem qualitativa seguida de outra, quantitativa, no exame da publicação jornalística. Iniciamos assim com a abordagem qualitativa do conteúdo oferecido pelo jornal, focalizando suas matérias referentes ao fato histórico em questão. Para fins de uma análise com enfoque qualitativo, foi selecionado o período de uma semana, de 29 de março de 2016 a 5 de abril do mesmo ano. No total, foram 81 artigos, 27 no caderno "Opinião", 35 no caderno "Poder", 3 no caderno "Cotidiano", 6 no caderno "Mercado", 5 editoriais, 5 no caderno "Ilustrada" e 2 no caderno "Mundo".

Nas últimas semanas antes da votação do processo de impeachment, pudemos acompanhar uma intensificação dos debates e discussões acerca do impedimento ou não do governo federal. Na imprensa, nas redes sociais, nos bares, nas casas, entre outros lugares, as conversações assumiam, muitas vezes, ares de uma disputa que se ensaiava nos cantos e recantos do país. Se por um lado o tema da política voltou a fazer parte da vida cotidiana brasileira, por outro, o debate ganhou forma de uma dicotomia maniqueísta, que provocou, paradoxalmente, a sua própria ruína. Se a política, nos regimes democráticos, é entendida, desde os gregos clássicos, como a atividade dos cidadãos que se ocupam dos assuntos públicos - e este é, sem dúvida, um assunto público - ela trata também da convivência entre os diferentes. Como recorda Arendt (1992), os homens e mulheres organizam-se politicamente para certas coisas em comum, a partir do caos das inevitáveis diferenças, mediante diálogos, negociações, debates para construção de consensos mínimos. De outro modo, a diversidade tanto é extinta quanto também é destruída a igualdade essencial dos humanos. A ruína da política surge do desenvolvimento da intolerância e da indisponibilidade para o diálogo.

No Brasil, especialmente, esse processo assume características singulares. Como destaca Marilena Chauí (1994), o Brasil é uma sociedade cujas relações sociais são manifestamente autoritárias, uma vez que "conheceu a cidadania através de uma figura inédita: o senhor-cidadão” (p. 53). É uma sociedade que forja a cidadania como um privilégio de classe, e na qual os direitos são concedidos aos demais estratos sociais (os não hegemônicos) de modo tutelado e estritamente regulado pelo Estado. Uma sociedade que naturaliza a desigualdade e a assimetria, configurando relações sociais de rígida hierarquização, ilustrada com provérbio popular: "manda quem pode, obedece quem tem juízo". Uma sociedade, ademais, na qual as leis não são instrumentos de definição de direitos e deveres para todos os cidadãos igualitariamente, mas "armas para preservar privilégios e o melhor instrumento para a repressão e a opressão” (Chauí, 1994, p. 54), igualmente bem ilustrado com outro conhecido provérbio popular: "aos amigos, tudo; aos inimigos, a lei”.

Nesse sentido, não causa surpresa a maneira maniqueísta com que o tema do impedimento ou não do governo federal vem sendo tratado e discutido habitualmente entre as partes de uma ou outra posição. A imprensa (eletrônica e impressa) tem ocupado papel crucial no acirramento deste processo, visto que, como documento de domínio público, detém o poder de promover e veicular amplamente as versões que circulam, tal como são assumidas e advogadas por aqueles que falam e consomem seus substratos simbólicos (Spink, 1999). Neste contexto, a questão decisiva que se coloca para a mídia jornalística e eletrônica é se ela, de fato, pretende e consegue abarcar no conteúdo veiculado a diversidade de posições sobre o tema a que se reporta. 


\section{Algumas considerações sobre as mídias}

As mídias materializam-se como espaços públicos de fala e, simultaneamente, como reconstrutores dos espaços públicos e privados, à medida que dão visibilidade à dinâmica das interações sócio-discursivas, das negociações e dos conflitos cotidianos vividos por atores sociais com seus saberes, fazeres, interesses e intencionalidades diversas. Se as mídias possibilitam este alargamento do alcance das narrativas locais para espaços-tempo nacionais e mesmo globais, elas também abrem um campo novo de possibilidades de colonização do mundo, ou seja, de manutenção das formas históricas de dominação (Habermas, 1984). A mídia jornalística, por exemplo, presentifica e torna conhecidas as falas e as vozes presentes nos cotidianos locais, que têm, muitas vezes, como efeito, naturalizar as assimetrias e o autoritarismo da sociedade brasileira.

São inúmeros os trabalhos contemporâneos que identificam a importância cada vez maior das mídias na construção das materialidades sociais e na redefinição dos espaços públicos e privados. Já na década de 1940, Adorno e Horkheimer (1985), mediante o conceito de Indústria Cultural, teciam considerações sobre os efeitos da expansão da produção dos elementos midiáticos sobre a organização societária e os processos de subjetivação. Para eles, a indústria cultural resulta da apropriação pelo capital dos meios de produção culturais, tornando-os mercadorias, ou seja, produtos regidos pelo princípio da equivalência, com valor de troca definido pelo mercado. Na mesma linha de pensamento, mas cerca de vinte anos mais tarde, Guy Debord publica $A$ Sociedade do Espetáculo, denominação que dá às sociedades nas quais os meios de comunicação de massa têm forte penetração nos espaços sociais.

Tanto para Adorno e Horkheimer (1985) quanto para Debord (1997), os meios de comunicação midiáticos - enquanto indústria cultural ou espetacularização da vida - participam efetiva e persuasivamente da produção e da circulação de narrativas que legitimam, justificam e criam as bases de sustentação do status quo das sociedades capitalistas atuais. Elas atuam no sentido de tornar as pessoas consumidores dóceis e obstinados, com reduzida capacidade crítica para com o ordenamento social vigente.

Habermas, em Mudança Estrutural da Esfera Pública (1984), embora em muitos aspectos diferente dos autores acima, compactua com sua visão no tocante aos efeitos da presença da comunicação de massa na esfera pública contemporânea. O autor distingue a esfera pública burguesa do Iluminismo, quando os espaços públicos, como os cafés e as praças, assim como os jornais, eram usados para debater abertamente posições da esfera pública mais recente, colonizada pelas mídias de massa, tornando-se por isso fictícia, uma encenação. Isso ocorreu, segundo Habermas, porque foi estreitado o corredor que propiciava e promovia a participação efetiva nas discussões para a construção da opinião pública. O debate, a racionalidade argumentativa, o embate de ideias, segundo o autor, deixaram de ser o critério principal na construção da opinião pública. A esfera pública agora é o lugar em que decisões - já concertadas em outras instâncias - conseguem a boa vontade do povo; e os meios de comunicação de massa assumem papel crucial nisso. O que era discussão transforma-se em sedução; o que era dimensão crítica transforma-se em dimensão manipulatória.

Tais autores fizeram escola entre os pensadores das mídias. No Brasil, não são poucos os estudos que se valeram de seus argumentos. Tragamos alguns: Kehl e Bucci (2004), em trabalho sobre a televisão, identificam-na como lugar de instauração de um novo espaço público, que opera seus elementos simbólicos impondo significações ideologizadas e extremamente sedutoras ao telespectador, que as apreende desejosamente, docilizando-se e conformando-se às intencionalidades das orientações dominantes. 
Guareschi (1999), em estudo sobre as relações entre meios de comunicação de massa e poder na América Latina, reflete sobre o uso que se faz deles para garantir a dominação de uma classe sobre outra. O mesmo autor, analisando as grandes mídias jornalísticas no país, conclui que as notícias são invariavelmente tratadas e modeladas de modo a adquirirem as cores ideológicas dos estratos dominantes.

Distintamente das concepções até aqui apresentadas neste tópico, que pressupõem as mídias de massa como instauradoras de uma esfera pública unívoca e homogeneamente dirigida pela voz do capital, Thompson (1995) argumenta pela possibilidade da polissemia de sentidos e das narrativas nelas presentificadas. Ele não recusa o papel preponderante das mídias nas sociedades contemporâneas, apenas rejeita a visão de um poder hipertrofiado das mesmas em sujeitar as pessoas que consomem seus elementos simbólicos. Ao invés disso, entende que a produção de sentidos e materialidades em torno das produções midiáticas é complexa, polissêmica e polivocal. Embora reconheça a grande transformação que as mídias provocaram nas esferas pública e privada, bem como as matizes ideológicas presentes em suas intencionalidades e estratégias de produção, Thompson assinala que as mídias são compostas por substratos materiais que mediam as comunicações. Elas estão permanentemente inscritas em redes socioculturais e históricas específicas, nos seus processos de produção (jornalistas, ensaístas, editores, patrocinadores, proprietários dos jornais) e de circulação e interpretação (consumidores dos elementos simbólicos por elas produzidos). Em cada um destes processos organizam-se práticas e relações sociais que estão enraizadas em estruturas sociais, materiais e culturais próprias, as quais possibilitam repertórios interpretativos e intencionalidades distintas - especialmente quando os veículos de comunicação em questão têm penetração nacional. Logo, os sentidos produzidos pelos que interpretam, por exemplo, uma informação transmitida pela televisão, não são necessária e exatamente os mesmos esperados pelos produtores da transmissão, devido às redes socioculturais e históricas nas quais estão inseridos os intérpretes. Estas são muitas vezes distintas das dos produtores -, e continuam a modificar-se em decorrência das conversas entre as pessoas sobre o que foi noticiado.

Entretanto, a importância que assumiram as mídias nas sociedades atuais é de modo algum contestada por Thompson. Como ele mesmo diz:

A produção e circulação das formas simbólicas nas sociedades modernas é inseparável das atividades das indústrias da mídia. O papel das instituições da mídia é tão fundamental, e seus produtos se constituem em traços tão onipresentes da vida cotidiana, que é difícil, hoje, imaginar o que seria viver num mundo sem livros e jornais, sem rádio e televisão e sem os inúmeros outros meios através dos quais as formas simbólicas são rotineira e continuamente apresentadas a nós. (Thompson, 1995, p. 219)

Diante disso, debruçar-se sobre como a questão do impedimento ou não do governo federal vem sendo tratada e presentificada na grande mídia é um procedimento que tem implicações políticas. A partir dele, buscaremos descortinar como se materializam as estratégias de colonização dos cotidianos utilizadas na grande imprensa, fazendo prevalecer seu próprio posicionamento político e concepção de mundo. 


\section{O discurso e a produção de sentidos}

Uma vez definido o campo de pesquisa (o jornal Folha de S. Paulo) e armazenado o corpus para a análise (período de uma semana de matérias jornal sobre o tema, de 25/03/2016 a 05/04/2016, conforme descrito acima, além de informações coletadas no website manchetômetro), partimos para a análise propriamente. Seguindo recomendações de Spink (1999), com leitura atenta e rigorosa, acompanhamos as histórias e as narrativas que se materializavam ao longo das páginas do jornal. Como ele mesmo ressalta,

Trabalhar com jornais, ou outro tipo de mídia estabelecida, requer o reconhecimento das regras a partir das quais os textos são gerados. Requer também a disposição de ler e acompanhar aquilo que é escrito dia após dia. Às vezes é possível identificar uma coluna regular ou uma parte do jornal que seja mais pertinente ao tópico em estudo, mas mesmo assim é necessário ampliar o olhar para ver o texto mais amplo dentro do qual o texto específico está sendo produzido. (Spink, 1999, p. 132)

Além disso, foi preciso que decidíssemos por uma concepção de discurso que nos instrumentalizasse no processo de análise do corpus. A concepção com a qual nos alinhamos faz referência a dois filósofos da linguagem: Bakhtin (1999) e Fairclough (2001, 2003). Tais autores provocam o rompimento da cisão, tradicionalmente presente na análise de discurso, entre abordagens que, de um lado, concentram-se na análise textual reduzindo a relevância dos aspectos estruturais do discurso e, de outro, debruçam-se mais fortemente nestes últimos aspectos. Diz Fairclough sobre isso:

A análise dos textos é uma parte essencial da análise de discurso, mas a análise de discurso não é meramente a análise linguística dos textos. Eu vejo a análise de discurso como oscilando entre um foco sobre textos específicos e um foco sobre o que chamo de 'ordem do discurso', a relativamente durável estrutura social da linguagem, que é um elemento da relativamente durável estrutura e rede das práticas sociais. (2003, p. 8)

Assim como Bakhtin, Fairclough parte do pressuposto de que discurso é ação social, é prática social e não mera representação ou tradução de algo, pois ele provoca efeitos. Discursos e textos podem mudar crenças e valores, podem produzir novos conhecimentos e procedimentos, mas podem também cristalizar e naturalizar o pré-existente. Decorre daí que separações entre ações sociais e palavras, entre real e significação do real são descartadas, pois se discurso é ação, tal ação dá sentido e materialidade ao mundo, às coisas, aos eventos e a cada um de nós em meio a tudo isso.

Para Bakhtin, esse processo de produção de sentidos é sempre dialógico. Diz ele: "A orientação dialógica é naturalmente um fenômeno próprio a todo discurso. Trata-se de uma orientação natural de qualquer discurso vivo. Em todos os seus caminhos até o objeto, em todas as direções, o discurso se encontra com o discurso de outrem e não pode deixar de participar, com ele, de uma interação viva e tensa” (1988, p. 88).

Todo discurso é, então, composto por intertextualidades, configurando-se como uma trama polidiscursiva, pois é sempre perpassado pelo(s) discurso(s) de outrem; ou seja, toda pessoa, mesmo quando em momentos de solidão reflexiva, considera, conscientemente ou não, o discurso de outrem para confeccionar o seu. Ela é, assim, sempre respondente. 
Fairclough (2003) argumenta ainda que o acontecimento discursivo, enquanto prática social dialógica e intertextual, mantém sempre uma interação indissociada com a situação, estrutura social e ou instituição que o enreda. Quer isso dizer que o acontecimento discursivo constrói-se pautado nas limitações e possibilidades de confecção dadas pela situação, estrutura e ou instituição que o marca, ou seja, ele é necessariamente formatado por elas. Mas ao mesmo tempo em que é formatado, também lhes dá forma, pois "constitui as situações, os objetos de conhecimento, a identidade social das pessoas e as relações destas e dos grupos entre si. As constitui no sentido de que contribui para sustentar e reproduzir o status quo, e também para transformá-lo" (Fairclough \& Wodak, 1997, p. 47).

Contemplar o discurso como um tipo de prática social com tantas possíveis orientações quanto às possibilidades de ações humanas e, por conseguinte, com vasto poder de influência nas estruturas das organizações e relações sociais requer, segundo Fairclough, enveredar pela campo das relações de poder e da ideologia que, para o autor, "são significações/construções da realidade (o mundo físico, as relações sociais, as identidades sociais) que são construídas em várias dimensões das formas/sentidos das práticas discursivas e que contribuem para a produção, a reprodução ou a transformação das relações de dominação" (Fairclough, 2001, p. 117). Com efeito, os processos de interanimação dialógica que se dão cotidianamente não são destituídos de tensões, embates, negociações em torno de interesses, crenças, valores, ideologias, em suma, não são destituídos das dimensões do poder. Localizar as relações de poder no âmbito das interanimações dialógicas exige lançar mão de novos conceitos para acompanhar a dinâmica dessas relações no cotidiano das práticas discursivas, no caso, no âmbito da mídia jornalística.

Com o conceito de voz, Bakhtin (1999) argumenta que um discurso é sempre expresso por meio de uma consciência falante, com intencionalidades e visões de mundo. Ele é sempre expresso por meio de uma voz. Porém, uma voz nunca é isolada, nunca é dissociada de outras vozes, sua existência só é possível como resultado das interações com outras vozes. A voz sempre produz um ou mais enunciados tendo como alvo certa direção, certo endereço, outras vozes, por assim dizer. Sejam nas situações de diálogo conversacional, em que ambas as vozes estão simultaneamente interagindo, sejam nas situações de interações mediadas (jornais, televisão), ou solitariamente em resposta a discursos imaginários internalizados, lidos ou ouvidos em algum instante da vida, todo locutor ou locutora opõe sempre uma "contrapalavra" (Bakhtin, 1999) à palavra de outrem.

Se por um lado o conceito de voz torna mais claro o que o autor concebe em sua teoria com o termo dialogia, por outro pode proporcionar equivocadamente uma aproximação com uma concepção individualizante. Em outras palavras, o conceito de voz pode levar a concluir que são individuais os fios preponderantes no processo de confecção do tecido discursivo. Bakhtin supera esse impasse propondo os conceitos de linguagens sociais e gêneros de fala. Com tais conceitos, ele apresenta a orientação dialógica como um campo extremamente dinâmico que contempla, no cotidiano das interações intervozes, a presença simultânea das singularidades das consciências falantes e das tipologias discursivas, ou seja, das normas e regulamentos discursivos - formal ou informalmente - estabelecidos, conforme as circunstâncias de uso. Tanto as linguagens sociais quanto os gêneros de fala remetem às regularidades discursivas utilizadas para produzirem seus enunciados nas diferentes composições dialógicas. As linguagens sociais referem-se às peculiaridades relativamente regulares, aos pacotes discursivos que cada classe, categoria ou estrato social acessa em determinada época e lugar. Já os gêneros referem-se às situações e temas típicos do dia a dia no processo dialógico como, por exemplo, o cumprimento que se faz a uma pessoa conhecida. 
Não se deve depreender disso, porém, uma existência independente e autônoma de tais pacotes discursivos - as linguagens sociais e os gêneros de fala -, como se fossem objetivos. Na vida real e humana, isso não faz sentido, pois qualquer que seja a pessoa em questão, embora se oriente pelos repertórios discursivos presentes nas linguagens sociais e gêneros de fala, apropria-se destes de maneira singular. Tudo o que se diz, escreve e pensa é, de algum modo, vivenciado dialogicamente. Para Bakhtin, aquilo que é vivenciado pelo ser humano o é dialogicamente -, é matizado e confeccionado a partir do lugar e tempo histórico no qual está posicionado. Assim,

Existe uma lei do posicionamento regulando a percepção humana: tudo o que é percebido só pode ser percebido a partir de um único ponto dentro de uma estrutura que agrega muitos pontos de visão. Nesse sentido, a percepção abriga um paradoxo: embora cada ser ocupe um único lugar na existência, ele nunca está sozinho. Por trás desse pensamento encontra-se a noção de como um eu é levado a se perceber na categoria de outro. (Machado, 1997, pp. 149-150)

Assim, na coluna de Rogério Gentile, no caderno "Opinião" - espaço nobre ao lado do editorial do jornal - de 31 de março de 2016, cuja manchete é “Dilma é par de Collor”, o autor se contrapõe à declaração anterior da presidente, quando ela comparou-se a Jango - referindo-se ao golpe que sofreu em 1964, que o depôs da presidência da República. Equipara-a, diferentemente, a Fernando Collor de Melo, ex-presidente deposto, já que tal como ele, segundo a coluna, Dilma comanda "uma gestão desmoralizada pela corrupção", "alvejada pelo líder de seu governo", está com baixíssima popularidade e "sem controle de base parlamentar". A intertex tualidade aqui é visível, à medida que o autor é respondente à declaração anterior de Dilma Rousseff. E ao fazer isso, endereça aos leitores e aos que participam ou acompanham o debate sobre o impeachment argumentos que justificam sua posição com relação ao tema.

Contemplar o discurso como entidade performática, ou seja, como um tipo de prática social que se orienta de modo dialógico e multivocal, pressupõe ainda enveredar pelo terreno das relações de poder. Pois os processos de interanimação dialógica que se dão cotidianamente não são destituídos de tensões, embates, negociações em torno de interesses, crenças, valores, ideologias, em suma, não são destituídos de poder.

A intertextualidade está, portanto, também imiscuída nesse processo de posicionamentos e embates retóricos na dialogia presentificada na arquitetura das matérias jornalísticas. Ela faz mediante a maneira como os textos constituem acréscimos às cadeias de comunicação existentes, apoiando-se em textos prévios aos quais respondem.

Com efeito, em coluna no caderno "Opinião", intitulada "Desembarque", de 30 de março de 2016, Hélio Schwartsman destaca "a ironia da esquerda ao se aferrar a supostos legalismos ou minudências jurídicas para tentar manter o mandato de Dilma", qualificando o pedido de impeachment, feito pela oposição, de golpe, uma vez que juridicamente não há caracterização de crime de responsabilidade identificável por parte da presidente. O autor alega que, curiosamente, a esquerda marxista nunca deu atenção para as questões jurídicas, tidas como do âmbito da "superestrutura voltada para manter as relações de produção em termos favoráveis à burguesia”, e partia do pressuposto de que as disputas de poder "não se dão pela via judicial, mas política”. E é, justamente, "a esfera política", argumenta o colunista, "que impedirá Dilma", à medida que ela perdeu sua base política com a decisão da saída do PMDB do governo, não podendo mais contar com os 171 deputados necessários para barrar o processo de impeachment. Schwartsman (2016) utiliza 
habilmente narrativa histórica da esquerda marxista para desqualificar os argumentos dos que acusam o pedido de impeachment de golpe, uma vez que, para sustentar esses argumentos, se aferram a preceitos jurídicos.Assim estes se contradizem, ou melhor, contradizem a história política da esquerda. Há, claramente, um embate retórico na coluna em questão a partir do qual o autor não apenas posiciona-se favorável ao impedimento da presidente, como constrói seu posicionamento buscando desqualificar os argumentos que sustentam o posicionamento dos que são contrários. Para tanto, traz para o texto a historicidade da narrativa da esquerda marxista para apontar as contradições dos oponentes.

\section{O jornal como documento de domínio público}

Como documento de domínio público, o jornal, segundo McLuhan (2001), assume a forma de um mosaico, no qual múltiplas falas justapostas acerca de cada assunto e de inúmeros assuntos presentificam-se, diariamente, ao longo de suas páginas. Ele promove e veicula, assim, uma diversidade de falas que refletem "o ir e vir de versões circulantes assumidas ou advogadas" em cada tempo (Spink, 1999, p. 136), mostrando-se como lugar de construção coletiva de sentidos e histórias, onde continuamente formam-se novos personagens, renovam-se os antigos e confrontam-se diferentes narrativas. Através do jornal, podemos acompanhar os embates retóricos na busca pela hegemonia de sentidos, e no caso específico deste ensaio, pelo embate em torno do sentido hegemônico acerca da legitimidade ou não do impeachment do governo Dilma Rousseff.

Como observa Mouillaud e Porto (2002, p. 117): "A respeito do jornal diário, não se poderia dizer que é um quarto de ecos onde ressoa o concerto de vozes que, sem ele, não teriam eco? Vozes discordantes por suas origens, seus conteúdos e seus locutores, caso sejam e devam ser autorizadas para se fazer escutar?" Mas, seria assim também no caso do jornalismo brasileiro contemporâneo?

A título de exemplo, não raro nos deparamos com notícias e colunas analíticas defendendo o impedimento do governo Dilma Rousseff como saída para a superação da crise que vive o país, como a entrevista de Paulo Remy Gillet, da empresa de construção civil WTorre, dada a repórter Joana Cunha, em 31/03/2016, no caderno "Economia”, cuja manchete é: "Governo precisa reconhecer que seu tempo passou, diz CEO da WTorre". Nela, o entrevistado aponta uma série de argumentos que justificam a saída de Dilma Rousseff, destacando, fundamentalmente, a perda de sua base política e da confiança do mercado em seu governo. De outro lado, artigos acusando o impeachment de golpe estão também presentes - embora em número expressivamente menor -, como o de Marcelo Freixo, colunista da Folha de S. Paulo, na época deputado estadual do Rio de Janeiro, de 05/04/2016, no caderno "Cotidiano", cujo titulo é "Espelho". Nele, o autor faz um breve histórico do cinismo político deste país, desde a independência, e convida os leitores a refletir acerca das artimanhas dos protagonistas do impeachment, mais preocupados com a tomada do poder do que com a necessária reforma política no país. Versões distintas, portanto, oriundas de vozes de lugares político-ideológicos e culturais distintos, dirigidas e marcadas por intencionalidades igualmente distintas. No entanto, além de veículo que presentifica vozes oriundas de diferentes lugares e com diferentes intencionalidades, o jornal também é um ator social; e como ator social que é, possui suas próprias versões e intencionalidades com respeito aos eventos que cobre. Isto pode ser verificado não somente nos artigos nos quais assume explicitamente suas posições, como nos editoriais. 
De fato, a voz do jornal mostra-se transversal às diversas matérias do jornal, seja de forma direta, como ocorre nos editoriais, seja de forma indireta, sutil. Na Folha de S. Paulo de 29 de março de 2016, no caderno "Poder", por exemplo, encontramos a notícia intitulada "Comissão de impeachment tem mais acusações de corrupção do que Dilma, diz jornal". A matéria se refere à publicação do jornal norte americano Los Angeles Times, do dia anterior, relatando que dos 65 membros da comissão de impeachment da câmara federal, 37 são acusados de vários crimes, como corrupção e lavagem de dinheiro. Relata também que dos 513 deputados federais, 303 são acusados ou investigados por envolvimento nestes crimes, e no senado são 49 dos 81 membros. O que parece ser um argumento de defesa do governo Dilma Rousseff contra o impeachment, passa sutil e gradativamente a mudar o tom no decorrer do texto. Ele destaca que, embora o artigo do Los Angeles Times relate que a presidente nunca tenha sido investigada por crime ou corrupção, vive um momento de extrema impopularidade, além de ser responsável pela crise econômica e política instalada no país. A matéria é concluída com a citação de editorial da revista britânica The Economist, que pede a renúncia de Dilma. Com ares de neutralidade e imparcialidade, o jornal expressa posição, na arquitetura deste artigo, simpática ao impedimento do governo Dilma.

Ainda em outro artigo, de 30 de março de 2016, a notícia intitulada "Impeachment sem crime de responsabilidade é golpe, diz Dilma", localizada no caderno "Poder", de autoria de Gustavo Uribe e Mariana Haubert, começa afirmando que o evento de lançamento do programa Minha Casa, Minha Vida 3 "foi transformado em palanque pela presidente". Descreve que Dilma Rousseff declarou que "os que querem tirar uma presidente sem base legal querem golpear direitos garantidos da população". E conclui dizendo que "o discurso foi feito no dia seguinte ao anúncio da saída do PMDB do governo”.

Novamente, o que parecia ser um posicionamento favorável ao governo, se nos detivermos apenas à primeira frase da manchete, começa a ficar ambíguo após a vírgula, uma vez que nomeia a própria presidente como autora da frase. Em seguida, no corpo do texto, lhe acusa de utilizar o lançamento da fase 3 do programa Minha Casa, Minha Vida - evento oficial do governo - de palanque para sua defesa junto à população. Ressalta que o evento em questão foi realizado logo após o anúncio de saída do PMDB (Partido do Movimento Democrático Brasileiro) do governo. A voz do jornal pode ser notada trespassando com certa sutileza o conjunto do artigo, e é ainda respaldado com uma notícia ao lado, cuja manchete é "Governo oferece ministério da saúde para evitar desembarque do PP”. O conjunto da página denuncia, sem defender o impeachment explicitamente, o uso que tem feito o governo da máquina pública do Estado (Minha Casa, Minha Vida e ministério da saúde, nestes casos) para se garantir no poder, tentando manter o Partido Popular (PP).

Em 2 de abril de 2016, a voz do jornal explicita sua posição no editorial deste dia. A manchete é "Nem Dilma nem Temer" e inicia afirmando que a presidente Dilma "perdeu as condições de governar o país" após o seu partido "protagonizar os maiores escândalos e corrupção de que se tem notícia”, além de qualificar a reeleição da presidente de estelionato eleitoral, uma vez que provocou forte recessão no Brasil ao contrário do prometido em campanha. Alerta ainda que as pedaladas fiscais, utilizadas pela oposição como motivo para justificar o impeachment, são legalmente questionáveis, o que levaria aos que ainda a apoiam - minoria, mas com penetração significativa na sociedade civil - a promover forte resistência pelo país afora. Diante disso, argumenta que o melhor caminho seria a iniciativa de Dilma para renunciar ao mandato. Destaca também que a renúncia deveria ser realizada também pelo vice-presidente Michel Temer, uma vez que não possui legitimidade junto à população para assumir a presidência. $\mathrm{O}$ editorial defende, assim, a renúncia de ambos e a marcação de novas eleições. 
Se durante o período inicial do processo de impedimento, que estava sendo gestado no meio político brasileiro, a Folha de S. Paulo manteve a abertura para posicionamentos divergentes, com o avanço do processo, ela foi convocada a assumir uma posição e o fez defendendo a renúncia da presidência e vice-presidência. Por um lado, ao defender a renúncia, não se compromete com a tese do impedimento, cuja fundamentação legal é questionável. Por outro, assumia um papel definitivo juntamente com todos que defendiam o afastamento da presidente eleita. O pedido de renúncia formulado por esse jornal evidencia a negociação entre os diferentes sentidos atribuídos aos acontecimentos dos meados de 2016: para os defensores do governo de Dilma, estava em curso um golpe com o objetivo de interromper o mandato presidencial sem justificativa legal. Para os opositores, tratava-se de remover do governo uma mandatária que já não reunia condições para o exercício do poder. É possível acompanhar, na data em questão e nos dias seguintes, a presença de matérias jornalísticas que expressavam o sentido de uma suposta ingovernabilidade no Brasil, particularmente na administração federal. Esta concepção vinha acompanhada de outro sentido: o de um apego ao cargo e aos poderes que ele concentra, que levariam, na posição veiculada pelo jornal, à adoção de práticas e posições antiéticas, visando sua manutenção no cargo de presidente. Dessa forma, no dia seguinte, quando o editorial denominado "Nem Dilma nem Temer" (2016) foi republicado ex traordinariamente na capa do jornal, encontra-se uma matéria com o título "PMDB dirá que governo promove 'mensalão' da Dilma" (Lima, 2016, p. A5). O texto evidencia uma suposta ilegalidade naquilo que foi e é prática corrente no meio político brasileiro: a construção de um arco de alianças acompanhada do compartilhamento da administração pública por forças políticas que se uniram.

É bastante significativo o formato que esta matéria ganha. Ela pretende noticiar o tipo de discurso a ser adotado pelos opositores do governo eleito na sua tentativa de deslegitimação do mesmo. Nesse sentido, constrói um discurso de natureza moral, no qual práticas consideradas desonestas e antiéticas são sistematicamente relacionadas com a governante eleita e sua equipe. A voz do jornal, nesse momento, entra em ressonância com o leque de forças políticas que atuam para a interrupção do mandato. Sob o pretexto de noticiar o discurso adotado, a Folha amplifica e multiplica esse discurso. Passa, assim, a imagem de que a saída da mandatária é uma necessidade, visto que a mesma adota procedimentos antiéticos e irregulares. Subsequentemente, a Folha veicula uma matéria que apresenta o Palácio do Planalto como sendo ocupado por um grupo político que pretende se salvar. O texto tem como título "Para salvar Dilma Lula mira votos do Norte e NE" (2016). Nele, o discurso adotado pelo jornal comporta uma condenação moral explícita ao mesmo tempo que reserva para si próprio a posição de agente moralizador da política.

De fato, o conteúdo dos jornais, pela pluralidade de posicionamentos eventualmente presentes, muitas vezes subsidiam a afirmação de que se trata de publicações pluralistas e imparciais. A análise dos enunciados da Folha de S. Paulo acima realizada começa a desmistificar tais afirmações, demonstrando que, mesmo com títulos aparentemente contrários ao afastamento da presidente, o que se explicita é a defesa do mesmo. Em sua defesa, os meios jornalísticos recorrentemente assinalam seu caráter "político, mas não partidário", para demonstrarem isenção diante da situação política brasileira. Um esforço dessa natureza está fadado ao fracasso. No mundo inteiro, os meios de comunicação são hoje compreendidos e analisados em função do poder que exercem, o que se traduz, no mais das vezes, na capacidade de intervir nos acontecimentos de natureza política atuando para que os mesmos resultem em certo desenlace. No caso da Folha de S. Paulo, a opção por 
formar uma opinião pública favorável ao afastamento da presidente é notável. Como vimos, diferentes setores do jornal emitem um posicionamento político alinhado e dirigido para legitimação do afastamento. Prevalece a orientação crítica à presidente. Nada impede que o mesmo veículo, eventualmente, apresente uma matéria discordante da sua linha política, como foi acima apresentado. Com frequência, matérias que se distanciaram das posições defendidas pelo jornal são relacionadas ao caráter pluralista e aberto às diferentes posições. O esforço empreendido nessa direção pode surtir um efeito inesperado, evidenciando para a opinião pública tanto a prática tendenciosa daquele órgão quanto sua tentativa de acobertá-la, abrindo-se, pontualmente, para opiniões discordantes da sua.

Independentemente desse tipo de iniciativa, os jornais, assim como os demais meios de comunicação, são cada vez mais reconhecidos pelo peso político que possuem. Em função desta constatação, cunhou-se a expressão "quarto poder" para designar o setor de comunicação, de modo a colocar em destaque sua capacidade de intervenção, ao lado dos três poderes que caracterizam o regime democrático.

Pode-se notar, assim, que o afastamento da presidente Dilma Rousseff se dá no âmbito de uma crise política continuada, que se avoluma desde o início do seu segundo mandato, em janeiro de 2015. Nesse contexto, o afastamento, considerado legítimo por um segmento da sociedade e ilegítimo por outro, possibilita também a abordagem quantitativa do posicionamento do jornal. Isso se torna possível pelo fato de que a questão do afastamento gravita em torno de uma oposição binária: contrário ou a favor do mesmo. Assim, à análise qualitativa realizada no conteúdo da Folha de S. Paulo, que evidenciou seu posicionamento favorável ao afastamento, vamos agregar uma abordagem quantitativa realizada sobre a sequência de manchetes produzidas sobre o evento em questão, mensurando quantas delas são favoráveis, neutras ou contrárias ao afastamento.

Encontramos no site "Manchetômetro", desenvolvido por pesquisadores ligados à UERJ, um conjunto sistematizado de dados sobre o jornal, que oferece evidências adicionais de que o posicionamento político é mantido na direção do impedimento do governo eleito e se dissemina por manchetes, capas, editoriais e reportagens. Nas palavras de seus organizadores:

O Manchetômetro é um website de acompanhamento diário da cobertura da política e da economia na grande mídia, especificamente nos jornais Folha de São Paulo, O Globo e Estado de São Paulo, e no Jornal Nacional, da TV Globo. O Manchetômetro é produzido pelo Laboratório de Estudos de Mídia e Esfera Pública (LEMEP), grupo de pesquisas com registro no CNPq, sediado no Instituto de Estudos Sociais e Políticos (IESP) da Universidade do Estado do Rio de Janeiro (UERJ). O Manchetômetro não tem qualquer filiação partidária ou com grupo econômico. (Manchetômetro, 2016)

A iniciativa deste coletivo de pesquisadores compreende a coleta e o tratamento de dados de quatro órgãos de comunicação que complementam a análise qualitativa do conteúdo das colunas e as reportagens já realizadas. Deste modo, o jornal poderá ser analisado no contexto da grande mídia impressa e televisiva brasileira. Como instrumento de coleta de dados, o Manchetômetro elaborou o índice de viés, que consiste em uma fórmula alimentada a partir da avaliação dos componentes da publicação (capa, editorial, manchetes e colunas). Cada um destes será categorizado como "contrário", "neutro" ou "a favor" do afastamento da presidente. Para operacionalizar essa análise, o índice de viés pode ser formulado como o número de matérias a favor do afastamento, menos o número de contrárias, dividido pelo número de 
matérias neutras. Cada matéria, capa, editorial ou coluna, é avaliada por dois pesquisadores e identificada com um dos posicionamentos. Em caso de empate, um terceiro pesquisador posiciona-se quanto ao conteúdo em questão. Os dados apresentados no sítio do Manchetômetro podem ganhar a forma de gráficos e, como veremos, evidenciam a larga predominância do posicionamento favorável ao afastamento da presidente. Primeiramente, vejamos na Figura 1 referente ao conteúdo das colunas mantidas pelos três jornais impressos analisados.

Figura 1: Impeachment nos jornais

\section{IMPEACHMENTNOS JORNAIS}

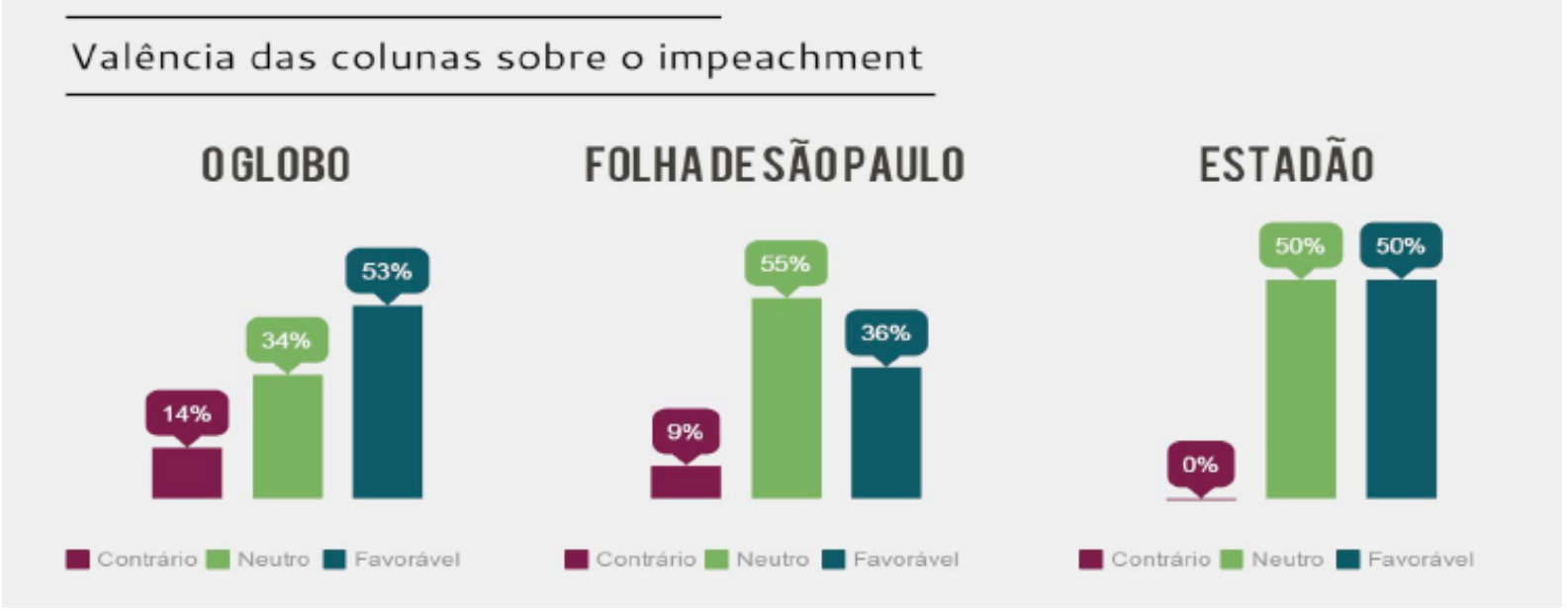

Fonte: Manchetômetro (2016).

No caso da Folha de S. Paulo, são identificadas quatro vezes mais colunas favoráveis ao afastamento (36\%) da presidente do que contrárias $(9 \%)$ ao mesmo. Quando os dados sobre a publicação são contextualizados em uma análise consolidada das três publicações brasileiras, o resultado surpreende. Tal como é anunciado na página, a proporção entre colunistas favoráveis e contrários ao impeachment é de 10 vezes mais colunistas favoráveis. (Manchetômetro, 2016). A análise quantitativa das colunas correlacionada com a análise qualitativa evidencia um direcionamento adotado, em bloco, pelos órgãos de comunicação. Estes atuam conjuntamente no sentido de formar, na opinião pública, a ideia de que o afastamento da presidente é o melhor desenlace para o momento histórico vivido pelo Brasil.

A sequência de manchetes de capa oferecida pelo jornal, se analisada conjuntamente, oferece um conjunto de dados sobre o posicionamento do jornal. Tais dados, como vimos, podem ser refletidos pelo instrumento da análise de viés, evidenciando o interesse do jornal, bem como seus esforços para que o acontecimento enunciado evolua em uma dada direção. Na página eletrônica do Manchetômetro, um acompanhamento sistemático das capas da Folha de S. Paulo feito entre janeiro de 2014 e maio de 2016 revela que, ao longo de todo esse período, o índice de viés manteve-se negativo, sendo que em alguns intervalos tornou-se altamente negativo. Predominam largamente assim as capas contrárias à permanência da presidente Dilma Rousseff, ao seu governo e ao seu partido. A constância do índice negativo evidencia a posição política do jornal, categoricamente contrária ao governo eleito. Os dados demonstram que o jornal desconsidera o tão propalado pluralismo de posicionamentos que, ostensivamente, se auto atribui. É o que pode ser visto na Figura 2: 
Figura 2: Índice de Viés - mensal no período de janeiro/2014 a julho de 2016

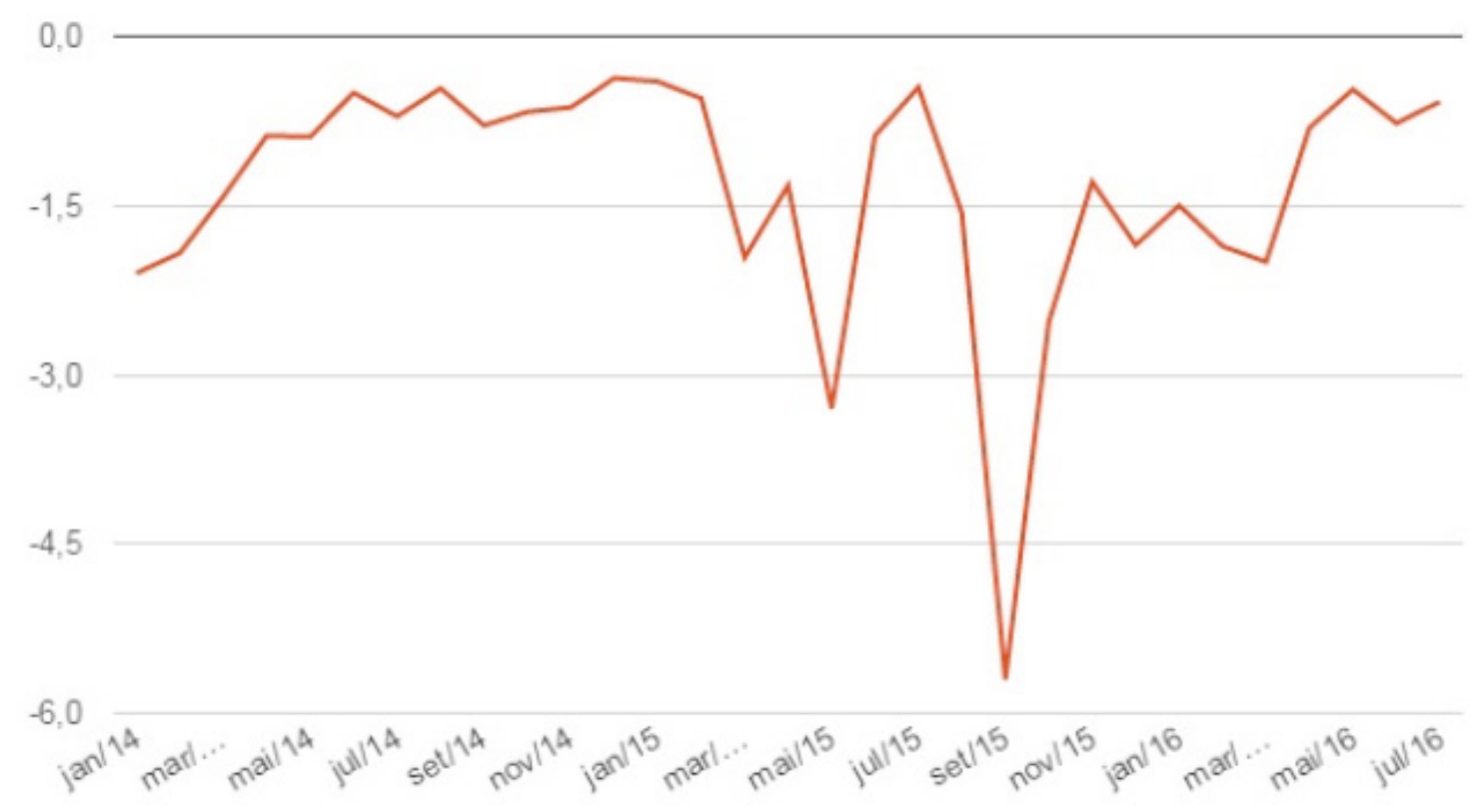

Fonte: Manchetômetro, 2016.

Ao acompanhamento longitudinal, é possível acrescentar o acompanhamento de um período menor, agora realizado sobre três componentes do jornal. O resultado, que pode ser visto na Figura 3, demonstra que em cada um dos componentes analisados (capas, editoriais e artigos de opinião) o viés manteve-se negativo na totalidade do período analisado, com largo predomínio de conteúdos contrários à manutenção da presidente.

Figura 3 - Índice de Viés - semanal de 08/05 - 30/07/2016

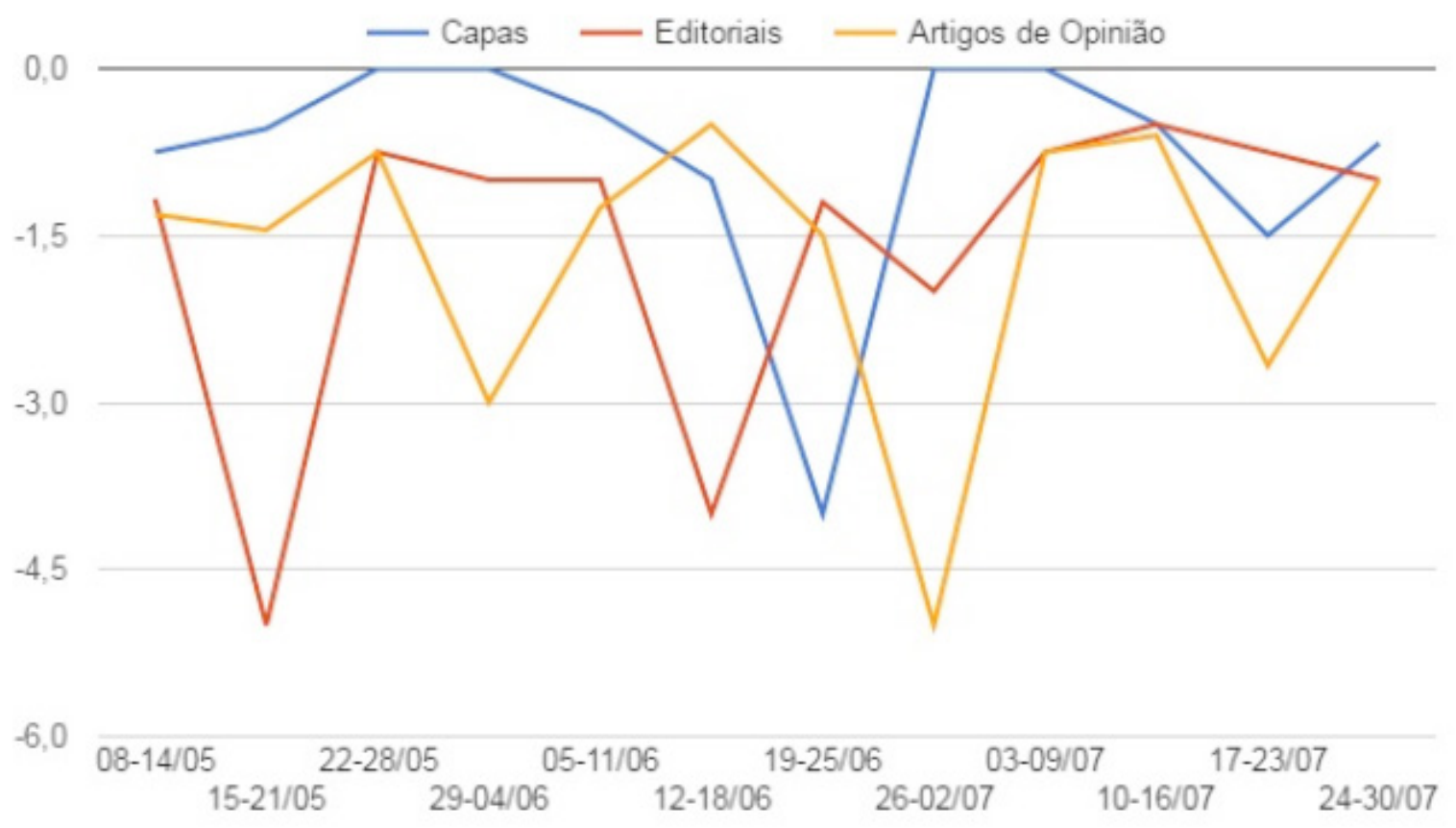

Fonte: Manchetômetro, 2016. 
As análises qualitativas e quantitativas realizadas sobre a Folha de S. Paulo e correlacionadas com os demais jornais brasileiros de grande circulação permitem delinear a presença anômala da mídia impressa no cenário político do Brasil. O alinhamento de posições sobre a presidente revela que o setor empresarial jornalístico compartilha convicções econômicas e políticas entre si e com outros segmentos sociais. Ela atua também no sentido de expandir o segmento social que compartilha tais posições. Isso não autoriza, no entanto, a difusão destas convicções, apresentadas como realidade factual. O exercício do poder jornalístico necessita ser confrontado por contrapoderes, sejam eles advindos do arcabouço institucional, sejam eles contrapoderes emergentes dos movimentos sociais.

\section{Considerações finais}

Os dados apresentados evidenciam uma situação preocupante do ponto de vista da manutenção da democracia. Tanto o maior jornal do país quanto o bloco dos maiores órgãos reproduzem um posicionamento coerente e articulado no sentido de desqualificar o governo eleito em 2014. Quando o processo de impedimento da presidente se instala, este bloco, que já havia atuado no sentido de legitimar sua instalação, passa agora a apresentá-lo como processo consumado, intervindo na opinião pública. A imprensa regional, muitas vezes consumidora de serviços jornalísticos dos grandes jornais, também se alinha, repercutindo o posicionamento político dos grandes órgãos de comunicação. Na mesma direção, segue o jornalismo eletrônico e televisivo que, com raras exceções, mantém-se em concordância com o bloco dominante. Nestes termos, cabe a pergunta feita pelo Manchetômetro: “Existe debate?”. Os dados demonstram que não. As 54 milhões de pessoas que elegeram Dilma Rousseff não se viram representados na cobertura jornalística. Retomando Bakhtin, as múltiplas vozes do cotidiano da sociedade brasileira não se expressaram no jornal. Em certa medida, a queda de popularidade da governante pode ser atribuída à cobertura jornalística enviesada oferecida pelo bloco dos meios de comunicação.

O quarto poder existe, é efetivo, mas no Brasil não se orienta pelo princípio democrático do respeito à diversidade de opiniões. O pluralismo de ideias, convicções e posicionamentos que os grandes jornais se atribuem simplesmente não existe. Se, eventualmente, capas e conteúdos contrariam o alinhamento político realizado, isto funciona como um sofisticado recurso propagandístico operacionalizado pelos jornais, no sentido de oferecer uma aparência de pluralidade. Às críticas dirigidas aos jornais, e de modo particular, à Folha de S. Paulo, tais como este próprio estudo, o bloco dominante da comunicação no Brasil responde dizendo que se trata do cerceamento da liberdade de imprensa. A sociedade brasileira necessita urgentemente problematizar a liberdade de imprensa. Tal como hoje ela é exercida, entra em conflito com as instituições democráticas. 


\section{Referências}

Adorno, T. \& Horkheimer, M. (1985). Dialética do Esclarecimento. Rio de Janeiro: Zahar.

Arendt, H. (1992). Entre o Passado e o Futuro. São Paulo: Perspectiva.

Bakhtin, M. (1988). Questões de Literatura e Estética. São Paulo: Hucitec.

Bakhtin, M. (1999). Marxismo e Filosofia da Linguagem. São Paulo: Hucitec.

Chauí, M. (1994). Conformismo e Resistência: aspectos da cultura popular no Brasil. São Paulo: Brasiliense. Comissão do impeachment tem mais acusações... . (2016). Folha de S. Paulo. Recuperado de https://www 1.folha.uol.com.br/poder/2016/03/1755095-comissao-do-impeachment-temmais-acusacoes-de-corrupcao-do-que-dilma-diz-jornal.shtml

Cunha, J. (2016). Governo precisa reconhecer... Folha de S. Paulo. Recuperado de https:// www 1.folha.uol.com.br/mercado/2016/03/1755833-governo-precisa-reconhecer-que-seutempo-passou-diz-ceo-da-wtorre.shtml

Debord, G. (1997). A Sociedade do Espetáculo. São Paulo: Contraponto.

Fairclough, N. (2003). Analysing Discourse: textual analysis for social research. Londres: Ruotledge. Fairclough, N. (2001). Discurso e Mudança Social. Brasília, DF: EdUnB.

Fairclough, N. \& Wodak, R. (1997). Análisis Crítico del Discurso. In T. A. Van Dijk (Org.), El Discurso como Interacción Social (pp. 79-203). Barcelona, ESP: Gedisa.

Freixo, M. (2016). Espelho. Folha de S. Paulo. Recuperado de https://www 1.folha.uol.com.br/ colunas/marcelo-freixo/2016/04/1757514-espelho.shtml

Folha de São Paulo - Institucional. Recuperado de http://www 1.folha.uol.com.br/institucional/ conheca a folha.shtml

Gentile, R. (2016). Dilma é par de Collor. Folha de S. Paulo. Recuperado de https://www1. folha.uol.com.br/colunas/rogeriogentile/

Guareschi, P. A. (1999). Comunicação e Poder: a presença e o papel dos meios de comunicação de massa estrangeiros na América Latina. Petrópolis, RJ: Vozes.

Habermas, J. (1984). Mudança Estrutural da Esfera Pública. São Paulo: Tempo Brasileiro.

Kehl, M. R. \& Bucci, E. (2004). Videologias. Rio de Janeiro: Boitempo.

Lima, D. (2016). PMDB dirá que governo promove 'mensalão da Dilma'. Folha de S. Paulo. Recuperado de https://acervo.folha.com.br/leitor.do? numero=20549\&keyword=Dilma\%2C Dilma\&anchor $=6020037$ \&origem $=$ busca\& mather $=\mathrm{b} 67 \mathrm{c} 84 \mathrm{feda} 2 \mathrm{e} 0 \mathrm{~b} 0 \mathrm{c} \& \mathrm{pd}=21 \mathrm{a} 54155 \mathrm{f} 6122$ e608f2c8cd2d928a9aa

Machado, I. A. (1997). Os Gêneros e o Corpo do Acabamento Estético. In B. Brait (Org.), Bakhtin, Dialogismo e Construção de Sentido (pp. 141-158). Campinas, SP: Unicamp.

Manchetômetro. (2016). Recuperado de http://www.manchetometro.com.br/

Mcluhan, M. (2001). Os Meios de Comunicação como Extensões do Homem (understanding media). São Paulo: Cultrix.

Mouillaud, M. \& Porto, S. D. (2002). O Jornal: da forma ao sentido. Brasília, DF: UnB.

Nem Temer nem Dilma. (2016). Editorial. Folha de S. Paulo. Recuperado de https://www1. folha.uol.com.br/opiniao/2016/04/1756924-nem-dilma-nem-temer.shtml 
Para salvar Dilma, Lula mira votos do Norte e NE. (2016). Folha de S. Paulo. Recuperado de https://acervo.folha.com.br/leitor.do?numero=20550\&keyword=Dilma\&anchor $=6020204 \&$ origem=busca\& mather=b67c84feda2eoboc\&pd=1b2cb2d8fc4ac23808651e 192f59bbe0

Schwartsman. H. (2016). Desembarque. Folha de S. Paulo. Recuperado de https://www 1.folha. uol.com.br/colunas/helioschwartsman/2016/03/1755347-desembarque.shtml

Spink, P. K. (1999). Análise de Documentos de Domínio Público. In M. J. Spink (Org.), Práticas Discursivas e Produção de Sentidos no Cotidiano (pp. 41-61). São Paulo: Cortez.

Thompson, J. B. (1995). Ideologia e Cultura Moderna: teoria social crítica na era dos meios de comunicação de massa. Petrópolis, Rj: Vozes.

Uribe, G. \& Haubert, M. (2016). 'Impeachment sem crime de responsabilidade é golpe’, diz Dilma. Folha de S. Paulo. Recuperado de https://www1.folha.uol.com.br/poder/2016/03/1755585impeachment-sem-crime-de-responsabilidade-e-golpe-diz-dilma.shtml

\section{PAULO ROBERTO DE CARVALHO}

\section{https://orcid.org/0000-0002-5732-5557}

Mestre em Psicologia Social e doutor em Psicologia Clínica pela PUC/

SP. Docente do Departamento de Psicologia Social e Institucional da Universidade Estadual de Londrina.

Endereço: Universidade Estadual de Londrina. Departamento de Psicologia Social e Institucional. Rod. PR 445. CEP 86051-990. Londrina / PR.

E-mail:paulor@uel.br

\section{ALEXANDRE BONETTI LIMA \\ https://orcid.org/o000-0001-9126-2919}

Doutor em Psicologia Social pela PUC/SP. Docente do Departamento de Psicologia Social e Institucional da Universidade Estadual de Londrina.

E-mail: bonetti@uel.br

\begin{tabular}{|c|c|}
\hline Histórico & $\begin{array}{l}\text { Sulbmissão: 01/11/2019 } \\
\text { Aceite: 06/12/2019 }\end{array}$ \\
\hline Contribuição & $\begin{array}{l}\text { Concepção: A. B. L.; P. R. C. } \\
\text { Coleta de dados: A. B. L.; P. R. C. } \\
\text { Análise de dados: A. B. L.; P. R. C. } \\
\text { Elaboração do manuscrito: A. B. L.; P. R. C. } \\
\text { Crítica de conteúdo intelectual importante: A. B. L.; P. R. C. } \\
\text { Aprovação final do manuscrito: A. B. L.; P. R. C. }\end{array}$ \\
\hline Financiamento & Não houve financiamento para a pesquisa. \\
\hline $\begin{array}{l}\text { Consentimento } \\
\text { de uso de imagem }\end{array}$ & $\begin{array}{l}\text { As imagens foram retiradas de documento de domínio } \\
\text { público com citação da fonte. }\end{array}$ \\
\hline
\end{tabular}

